Diabetologia (1994) 37: 930-936

\title{
Differences in umbilical cord insulin and birth weight in non-diabetic pregnancies of women from different ethnic groups in New Zealand
}

\author{
D. Simmons \\ Department of Medicine, Middlemore Hospital, University of Auckland, Auckland, New Zealand
}

\begin{abstract}
Summary Many ethnic groups at high risk of non-insulin-dependent diabetes mellitus are hyperinsulinaemic by early adult life. This study assessed whether such hyperinsulinaemia is present at birth. Cross sectional comparisons of maternal biochemistry, umbilical cord biochemistry and neonatal anthropometry were made between one 'low risk' and three 'high risk' ethnic groups, without diabetes in pregnancy in Auckland, New Zealand. The study comprised 123 European, Polynesian (Maori and Pacific Islands) and Indian normal pregnancies. Indian mothers were the smallest, with the highest insulin and non-esterified fatty acid concentrations. Polynesian mothers were the most obese with a higher fructosamine concentration. From these pregnancies, Indian neonates were smaller, slimmer, with the highest cord triglyceride $(0.6 \mathrm{mmol} / \mathrm{l}$ vs $0.4 \mathrm{mmol} / \mathrm{l}$,
\end{abstract}

$p<0.01$ ), and lowest cord insulin concentrations (7.1 mU/1 vs $8.6 \mathrm{mU} / 1$ (European), $9.2 \mathrm{mU} / 1$ (Polynesian), $p<0.05)$. Polynesian babies had a high cord insulin: C-peptide ratio $(52.5 \mathrm{mU} / \mathrm{nmol}$ vs $44.4 \mathrm{mU} /$ nmol (European), $44.1 \mathrm{mU} / \mathrm{nmol}$ (Indian), $p=0.05$ ). Although reduced intrauterine growth may contribute to the excess of diabetes and heart disease in Indians, it cannot explain the excess of diabetes in Polynesians. Exposure to minor relative maternal hyperglycaemia in the mother and abnormal neonatal insulin handling (as demonstrated by the higher insulin: C-peptide ratio) may be of long-term significance in Polynesians. [Diabetologia (1994) 37: 930-936]

Key words Insulin, C-peptide, fructosamine, triglyceride, birthweight, fatty acid, non-insulin-dependent diabetes mellitus.
The pathogenesis of NIDDM remains obscure. Two risk factors which have been identified for future NIDDM diabetes are previous gestational diabetes [1] and belonging to certain ethnic groups [2]. In prospective studies, NIDDM is preceded by a moderate elevation in plasma glucose in spite of a high plasma insulin [3, 4]. Non-diabetic relatives of NIDDM patients [5] and ethnic groups at high risk of NIDDM

Received: 7 December 1993

and in revised form: 13 April 1994

Corresponding author: Dr. D.Simmons, Academic Teaching Unit, Middlemore Hospital, Otahuhu. Auckland 6, New Zealand

Abbreviations: NIDDM, non-insulin-dependent diabetes mellitus, OGTT, oral glucose tolerance; NEFA, non-esterfied fatty acids.
$[6,7]$ have high mean plasma glucose and insulin concentrations. Both the relative hyperinsulinaemia and hyperglycaemia are present at a young age $[6,8]$, suggesting that the mechanisms leading to NIDDM commence early in life. Recent work in England has shown a relationship between low birth weight and risk of diabetes both alone [9], and in the presence of hypertension and hyperlipidaemia (syndrome X) [10]. Intrauterine starvation has been postulated to explain these effects [11]. However, others have suggested that exposure to hyperglycaemia in utero also predisposes to future NIDDM [12].

Auckland, New Zealand (population approximately 950,000) is the largest Polynesian city in the world, with over 200,000 Maori and Pacific Island residents. A small Indian community also exists population approximately 10,000 ) who migrated predominantly via Fiji. Recent work has confirmed a high pre- 
valence of NIDDM in local Maori, Pacific Island and Indian communities [13], and diabetes is perceived as a major public health issue. This study has assessed whether abnormal anthropometry, insulin and fuel metabolism can be detected at birth among babies from mothers at high risk of future NIDDM because of ethnic origin.

\section{Subjects and methods}

Consecutive Euorpean, Maori, Indian and Pacific Island women with singleton pregnancies were recruited between February and October 1991 from the antenatal clinics of the Middlemore and National Women's Hospitals at approximately 28-30 weeks' gestation. Gestational age was assessed clinically, with ultrasonography where possible. Women were approached either directly at the clinic or by telephone, and were excluded if they smoked more than 10 cigarettes per day, had any medical or endocrine condition, had booked late at the clinic or who were poor clinic attenders. As non-diabetic Europeans were considered the low risk "control" group, European women who had a parent with a known family history of diabetes were also excluded. Maori couples were only included if three or four of their parents were considered Maori, while in other ethnic groups all four parents were the same. Women received a $100 \mathrm{-g}$ oral glucose tolerance test and those with gestational diabetes according to modified O'Sullivan criteria [14] were excluded.

Following recruitment into the study, women were later excluded antenatally if they developed an obstetric complication such as intrauterine growth retardation (diagnosed clinically and by ultrasound) or hypertension/pre-eclampsia. At delivery, women who had difficult deliveries (significant meconium and/or fetal distress on cardiotocography) or who delivered prematurely ( $<37$ weeks by clinical criteria or by ultrasound) were excluded. Women received intravenous therapy at delivery when clinically indicated (e.g. dehydration, epidural, syntocinon infusion). The protocol for the study was approved by the Auckland Area Health Board Ethics Committee and informed consent was obtained from each subject.

Maternal clinical and metabolic investigations. On recruitment, a questionnaire was completed including demographic details, known maternal and paternal family history of diabetes, past obstetric and smoking history. Height on recruitment, and booking in weight (under 20 weeks) were recorded. Women were invited to undergo a $3-\mathrm{h}, 100$-g OGTT between 28 and 32 weeks' gestation while a fasting venous sample was taken at 36-38 weeks for glucose, fructosamine, insulin, C-peptide, $3 \beta$-hydroxy-butyrate, NEFA and triglyceride concentrations. The maternal pre-delivery weight was recorded as the last clinic weight before delivery. The mother had a capillary sample taken for glucose concentration within $5 \mathrm{~min}$ of delivery of the baby.

Cord blood sampling. Immediately following delivery of the baby at term, the umbilical cord was clamped $2 \mathrm{~cm}$ from the neonate and as near to the introitus as possible. The cord was cut, and umbilical venous blood was taken from the clamped cord using syringe and needle under supervision (of the author). Samples were collected for glucose, fructosamine, insulin, C-peptide, $3 \beta$-hydroxy-butyrate, NEFA and triglyceride concentrations. Serum and plasma were separated within $15 \mathrm{~min}$ of collection and stored at $-20^{\circ} \mathrm{C}$ until assayed. Gesta- tional age was assessed using Dubowitz criteria [15] with babies considered to be of less than 37 weeks gestation excluded from the study.

Neonatal anthropometry. Birth weight was taken using Toledo scales in the delivery unit. The baby was visited within $24 \mathrm{~h}$ for anthropometric measures by the author. All measures were taken as the mean of three recordings. Skinfold measurements were taken on the left side. Head circumference (CV: $0.9 \%$ ) was taken at the largest circumference with a tape measure and crown rump length using a baby board (CV: $1.2 \%$ ). Waist (CV: $1.6 \%$ ) was measured as the smallest circumference below the costal margin and hip (CV: 1.1\%) at the level of the most lateral point on the greater trochanter. Skinfold thicknesses were measured using paediatric skinfold callipers (Holtain Ltd, Dyfed, Pembs, UK) calibrated to $0.2 \mathrm{~mm}$. Biceps (CV: $8.8 \%$ ), triceps (CV: $7.6 \%$ ), subscapular (CV: $5.8 \%$ ) and suprailiac (CV: 6.7\%) measurements were taken.

Assays. Glucose, fructosamine, $3 \beta$ hydroxy-butyrate and triglyceride concentrations were measured in batches on a Hitachi 717 autoanalyser (Hitachi, Japan) (interassay precision $1.9 \%$, $2.7 \%, 11.8 \%$ and $2.0 \%$, respectively). Blood for capillary glucose estimation was collected into a heparinised capillary tube and analysed on a Beckman glucose oxidase 2 analyser (Beckman, Palo Alto, Calif., USA). The insulin was assayed by an enzyme-immunological test for human insulin using a kit (Boehringer Mannheim, Mannheim, Germany). Cross reactivity with proinsulin is $40 \%$ and the interassay precision is $4.8 \%$. Blood for C-peptide was collected into trasylol and measured by a radio immunoassay kit (Novo-Nordisk, Bagsvaerd, Denmark) with an interassay precision of $5.0 \%$. Plasma NEFA concentration was assayed using an enzymatic colorimetric system [16], with an interassay precision of $3.6 \%$.

\section{Statistical analysis}

All tests are two tailed, with a $5 \%$ significance level taken as significant, and were performed using SPSS-PC (SPSS inc, Chicago, Ill., USA). Mean \pm SD is shown for normally distributed continuous variables and median (range) for non-normal continuous variables. Non-normally distributed continuous variables were logarithmically transformed for analysis and geometric means are shown. Maternal physical and OGTT characteristics, and neonatal characteristics were compared by analysis of variance (continuous variables) or chi-square test (discrete variables) to compare. Adjustment of maternal biochemical data for continuous variables was made by analysis of covariance (e.g. for maternal body mass index), and adjustment for discrete variables was made by either direct standardisation or multiple analysis of variance (MANOVA). Univariate correlations were performed using Spearman's correlations $\left(r_{\mathrm{s}}\right)$ and multivariate analyses by stepwise regression with significance taken at $p<0.05$.

\section{Results}

In total, 191 mothers were invited into the study and $65 \%$ completed the study (Table 1 ). Of the 68 women leaving the study, $53 \%(n=36)$ changed their minds after recruitment (and consultation with spouse or relative) or moved from the area, 15 were excluded prior to delivery for obstetric reasons ( 5 
Table 1. Physical characteristics of maternal subjects

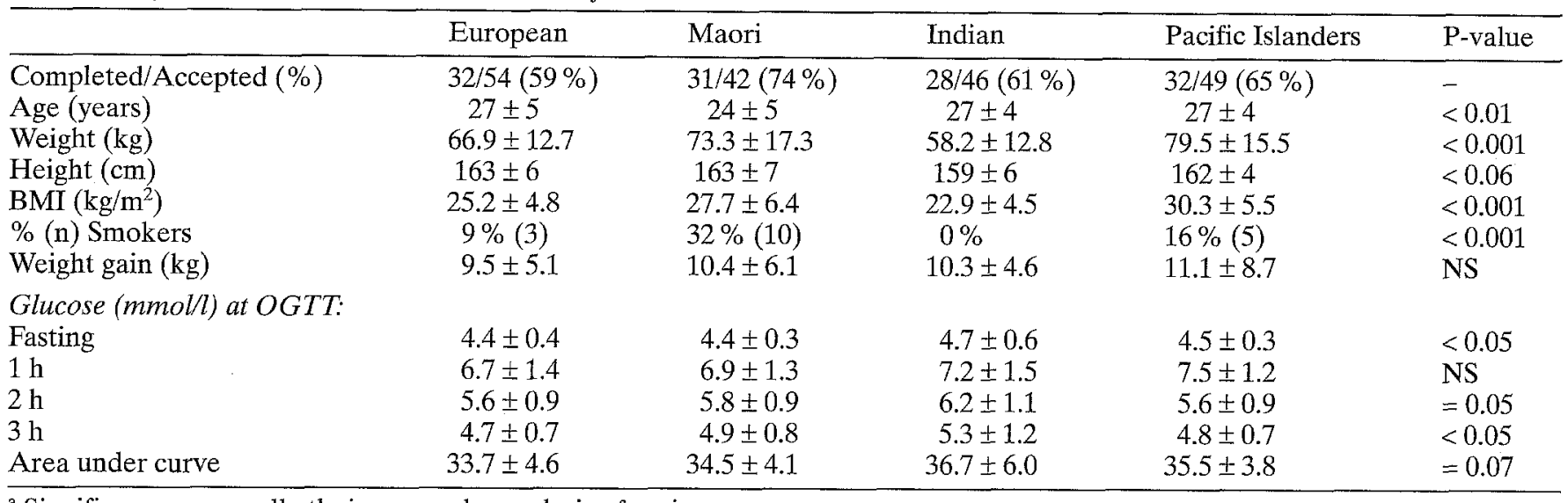

a Significance across all ethnic groups by analysis of variance

Table 2. Biochemical characteristics of maternal subjects at 36 weeks gestation and in umbilical cord blood

\begin{tabular}{|c|c|c|c|c|c|c|c|c|}
\hline & \multicolumn{4}{|l|}{ Maternal } & \multicolumn{4}{|c|}{ Umbilical cord } \\
\hline & European & Polynesian & Indian & sig $^{a}$ & European & Polynesian & Indian & $\operatorname{sig}^{b}$ \\
\hline $\begin{array}{l}\text { Fructosamine } \\
(\mu \mathrm{mol} / \mathrm{l})\end{array}$ & $214 \pm 14$ & $223 \pm 15$ & $215 \pm 12$ & 0.01 & $204 \pm 22$ & $212 \pm 26$ & $210 \pm 26$ & NS \\
\hline $\begin{array}{l}\text { Glucose } \\
(\mathrm{mmol} / \mathrm{l})\end{array}$ & $5.3 \pm 0.5$ & $5.1 \pm 0.5$ & $5.0 \pm 0.7$ & NS & $5.5 \pm 1.1$ & $5.4 \pm 1.1$ & $5.8 \pm 1.1$ & NS \\
\hline $\begin{array}{l}\text { Insulin } \\
(\mathrm{mU} / 1)\end{array}$ & 9.6 & 11.2 & 13.5 & 0.01 & 8.6 & 9.2 & 7.1 & 0.05 \\
\hline $\begin{array}{l}\text { C-peptide } \\
(\mathrm{nmol} / \mathrm{l})\end{array}$ & 0.40 & 0.38 & 0.36 & NS & 0.27 & 0.24 & 0.23 & NS \\
\hline $\begin{array}{l}\text { Insulin/C-peptide } \\
(\mathrm{mU} / \mathrm{nmol})\end{array}$ & 44.8 & 54.7 & 56.6 & 0.02 & 44.4 & 52.5 & 44.1 & 0.05 \\
\hline $\begin{array}{l}\text { Insulin/glucose } \\
\text { (mU/mmol) }\end{array}$ & 3.4 & 4.2 & 4.0 & 0.07 & 2.2 & 2.4 & 1.8 & 0.06 \\
\hline $\begin{array}{l}3 \beta \text {-hydroxy butyrate } \\
(\mathrm{mmol} / \mathrm{l})\end{array}$ & 0.052 & 0.061 & 0.062 & NS & 0.25 & 0.21 & 0.17 & NS \\
\hline $\begin{array}{l}\text { NEFA } \\
(\mathrm{mmol} / \mathrm{l})\end{array}$ & 0.36 & 0.34 & 0.52 & 0.002 & 0.19 & 0.17 & 0.19 & NS \\
\hline $\begin{array}{l}\text { Triglyceride } \\
(\mathrm{mmol} / \mathrm{l})\end{array}$ & 2.4 & 2.5 & 2.4 & NS & 0.4 & 0.4 & 0.6 & 0.01 \\
\hline $\begin{array}{l}\text { Capillary glucose } \\
\text { at delivery (mmol/l) }\end{array}$ & $6.4 \pm 1.0$ & $6.4 \pm 1.0$ & $6.3 \pm 1.1$ & NS & & & & \\
\hline
\end{tabular}

a Significance adjusted for maternal BMI by analysis of covariance

bignificance across normal subjects by analysis of variance

Geometric means are shown for insulin, C-peptide, insulin ratios, NEFA and $3-\beta$ hydroxy butyrate

with pre-eclampsia/hypertension) and 17 at delivery with fetal distress, delivery before arrival at hospital or who were missed. There were no ethnic group differences in reasons for leaving the study, and those not continuing were similar regarding age, height, body mass index, weight gain in pregnancy and birth weight, as those remaining in the study. However, those leaving the study delivered 1 week earlier on average $(p=0.005)$.

Among mothers, there were no significant ethnic group differences in parity $(1(0-5))$, gestational age at OGTT (34 \pm 3 weeks) and at delivery $(40 \pm 1$ weeks), duration of labour $(7(0-27 \mathrm{~h}))$, or mode of delivery (17\% Cesarean or forceps). Table 1 demonstrates that Maori women were younger than the other three ethnic groups, Indians were shorter, and that Indians had a lower, and Maori and Pacific Island women a higher body mass index than Europeans. Maori women were most likely to continue to smoke, in spite of the exclusion of those smoking more than 10 cigarettes per day. Indians had a consistently high glucose concentration during the OGTT. As there were no significant differences between Maori and Pacific Island patients (Polynesians) besides age and smoking, these two groups have been merged for analysis. 
Table 3. Anthropometry of babies

\begin{tabular}{lcccc}
\hline & European & Polynesian & Indian & sig $^{\mathrm{a}}$ \\
\hline Birth weight (kg) & $3.46 \pm 0.59$ & $3.55 \pm 0.50$ & $3.00 \pm 0.53$ & 0.001 \\
Subscapular (mm) & $5.3 \pm 1.2$ & $5.5 \pm 1.4$ & $4.4 \pm 1.1$ & 0.001 \\
Waist (cm) & $27.4 \pm 1.9$ & $27.6 \pm 1.7$ & $25.8 \pm 1.7$ & 0.001 \\
Hips (cm) & $29.6 \pm 2.5$ & $29.9 \pm 2.1$ & $28.2 \pm 2.6$ & 0.005 \\
Head circumference (cm) & $35.1 \pm 1.5$ & $35.6 \pm 1.3$ & $34.1 \pm 1.2$ & 0.001 \\
Crown-rump (cm) & $33.3 \pm 1.6$ & $33.7 \pm 1.4$ & $32.1 \pm 1.5$ & 0.001 \\
Calliper sum (mm) & $18.5 \pm 3.6$ & $18.9 \pm 3.7$ & $16.4 \pm 3.1$ & 0.02 \\
Subscapular: triceps ratio & $1.4 \pm 0.3$ & $1.3 \pm 0.2$ & $1.1 \pm 0.1$ & 0.002 \\
\hline
\end{tabular}

a Significance across normal subjects by analysis of variance

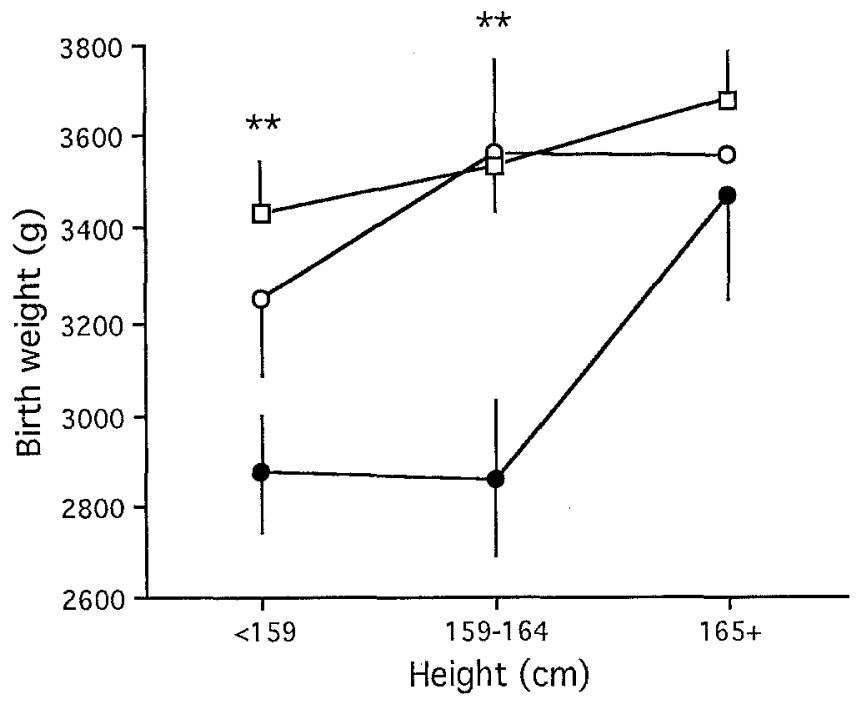

Fig. 1. Relationship between birth weight and maternal height by ethnic group. Europeans (O); Polynesians ( $\square$ ); Indians ( $\bullet$ ). ** $p<0.01$ difference between ethnic groups. Height is divided by tertile. Error bars show \pm SEM

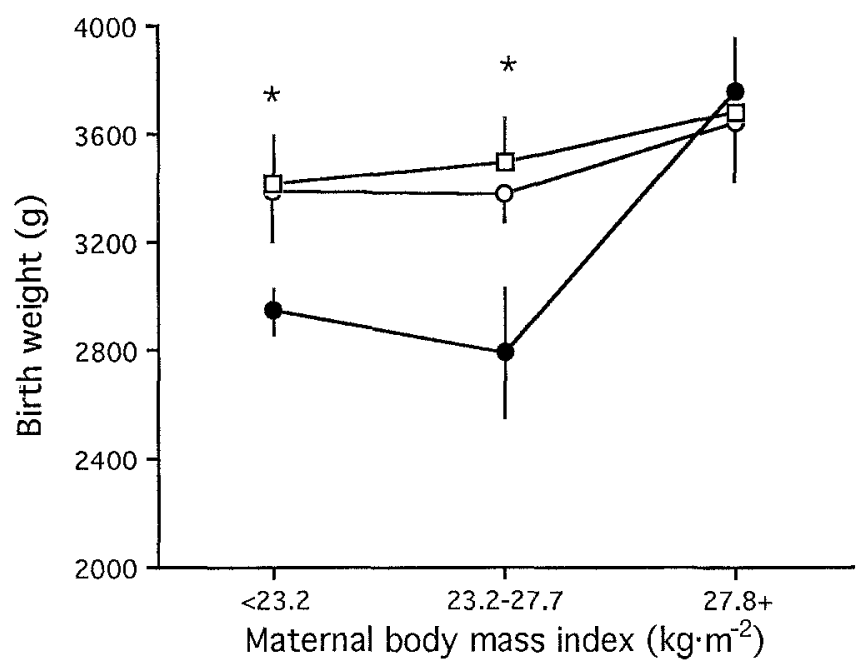

Fig. 2. Relationship between birth weight and maternal body mass index by ethnic group, after adjusting for maternal fasting glucose at 36 weeks gestation. Europeans $(O)$; Polynesians $(\square)$; Indians $(\bullet)$. * indicates $p<0.05$ difference between ethnic groups. Body mass index is divided by tertile. Error bars show \pm SEM

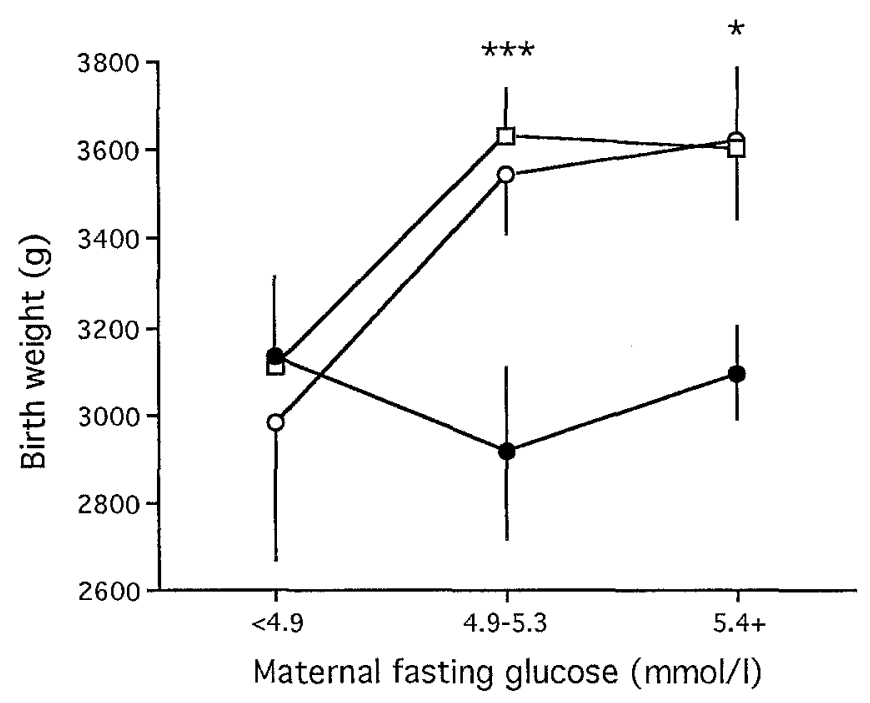

Fig.3. Relationship between birth weight and maternal fasting glucose at 36 weeks gestation by ethnic group after adjusting for maternal body mass index. Europeans ( $O$ ); Polynesians $(\square)$; Indians $(\bullet)$. * indicates $p<0.05$ and $* *$ indicates $p<0.001$ difference between ethnic groups. Fasting glucose is divided by tertile. Error bars show \pm SEM

Table 2 shows the maternal metabolic profile at 36-38 weeks. Polynesian mothers had high fructosamine, and Indians high NEFA concentrations. Insulin: glucose ratio, insulin: C-peptide ratio and insulin concentrations were higher in Polynesians and Indians even after adjusting for body mass index. The fasting glucose at this time was similar in the three groups. Table 2 also shows the umbilical cord biochemistry and demonstrated a low cord insulin concentration, a high triglyceride concentration and a low insulin: C-peptide ratio in Indian babies. Polynesian babies had a high insulin: glucose ratio. There were no ethnic group differences in cord glucose concentration or maternal capillary glucose concentration at delivery.

The maternal capillary glucose concentration at delivery did not correlate with duration of labour or parity (although labour and parity were correlated $\left.\left(r_{\mathrm{s}}=-0.31, p<0.001\right)\right)$. The glucose concentration was higher among women who had normal $(6.3 \pm 0.9 \mathrm{mmol} / \mathrm{l})$ and assisted (with Syntocinon) 
$(6.2 \pm 1.1 \mathrm{mmol} / \mathrm{l})$ deliveries than with forceps $(5.8 \pm 1.0 \mathrm{mmol} / \mathrm{l})$ and Cesarean section deliveries $(5.6 \pm 1.1 \mathrm{mmol} / 1, p<0.02)$, possibly because of the use of epidural anaesthesia.

Table 3 demonstrates the similar weight, skinfold thickness and other anthropometric measurements in European and Polynesian babies. There were no ethnic differences in triceps skinfold thickness $(4.0 \pm 1.0 \mathrm{~mm} \mathrm{Hg}$ overall) or waist: hip ratio $(0.92 \pm 0.04$ overall). The suprailiac thickness was lower in Indians $(p<0.05)$. Indian babies were lighter, with smaller calliper measurements and with smaller bony structures (head circumference and crownrump length). The relationships between birth weight and height, birth weight and body mass index (after adjusting for maternal glucose) and birth weight and maternal glucose (after adjusting for maternal body mass index) are shown for each ethnic grouping in Figures 1-3. Maternal height did not explain the lower birth weight of the Indian babies when compared with the other ethnic groups. Although birth weight was similar in the three groupings in the highest tertile $\left(\mathrm{BMI} \geq 27.8 \mathrm{~kg} \cdot \mathrm{m}^{-2}\right.$ ), (which included only four Indian subjects), Indian babies were otherwise smaller when matched for body mass index. While the Indian birth weight was unrelated to the maternal glucose at 36 weeks, European and Polynesian babies had a significantly higher birth weight with a glucose more than $4.9 \mathrm{mmol} / \mathrm{l}$. This was associated with both larger skinfold measures (e.g. subscapular $p<0.05)$ and bony measures (e.g. head circumference $p<0.001$ ).

\section{Discussion}

The principal hypothesis being tested in this study was that babies from mothers at high risk of diabetes would be hyperinsulinaemic. The lower insulin concentration in Indian babies was unexpected. In view of the well-described hyperinsulinaemia in adult Indians $[6,8]$, this finding indicates that insulin concentrations increase after birth. Explanation for this low umbilical cord insulin concentration needs to be incorporated into any hypothesis on the aetiology of NIDDM in Indians, and is consistent with insulin deficiency rather than insulin resistance [17] being present as an initiating feature (at least in Indians). It was not possible in this study to differentiate between an inherited and an intrauterine cause for this low insulin concentration.

It is possible that those Indian women who had a higher insulin or glucose concentration when nonpregnant had developed gestational diabetes and had been excluded from the normal Indian group. However, the higher insulin: glucose ratio, insulin and NEFA concentrations in the Indian mothers suggests that a least some insulin resistant women re- mained. Another possible explanation for the lower insulin in Indian babies could be their smaller size, a well-reported attribute of Indian babies [18]. Although the ethnic differences in insulin disappeared on adjusting for birth weight, this cross sectional design cannot be used to assess whether the low insulin or the low birth weight came first. However, as insulin stimulates growth [19] it is possible that the babies were small because of their lower insulin concentration.

The striking difference in anthropometric and metabolic characteristics between Polynesian and Indian babies, despite having a similar risk of future NIDDM, suggests different aetiologies for NIDDM in the two groups. A recent hypothesis [12], relates a low birth weight with a high risk of both ischaemic heart disease and NIDDM. The small size of the Indian babies, from a population with both a high prevalence of NIDDM [6], and a high incidence of ischaemic heart disease [20] fits perfectly with this hypothesis. In contrast, Polynesian babies were of a similar size to European babies, suggesting that the small baby hypothesis does not apply to these ethnic groups. Interestingly, although all Polynesians have a high risk of NIDDM [13], Pacific Island people have a low risk of ischaemic heart disease [21]. Risk for ischaemic heart disease in Maori people is difficult to interpret because of the very high proportion who smoke (up to $70 \%$ ) [22].

Pima Indians, another ethnic group with a high prevalence of NIDDM [2], appear similar to Pacific Island people in having a low incidence of ischaemic heart disease [23]. They also have babies of similar or larger size than Europeans [24]. A recent hypothesis, derived from a 25-year follow up of Pima babies, suggests that a predisposition to NIDDM in this group could arise from in utero exposure to maternal hyperglycaemia [12]. This is further supported by animal experiments, where diabetes in pregnancy was induced by streptozotocin [25] or glucose infusion [26] in the $\mathrm{F}_{0}$ rat generation, and is followed by the development of diabetes in the $\mathrm{F}_{1}$ and $\mathrm{F}_{2}$ generations. However, the mechanism by which this predisposition occurs is unknown. Polynesian mothers had a higher fructosamine (with normal OGTTs), and their neonates had a higher insulin: $\mathrm{C}$-peptide ratio. The latter suggests, abnormal insulin processing. It is conceivable that this relative hyperglycaemia in nondiabetic Polynesian mothers could be associated with increased fetal exposure to in utero hyperglycaemia, and long-term increases in risk of diabetes in subsequent generations.

The higher triglyceride concentration in the Indian cord blood is another new finding and could contribute to the increased susceptibility of Indians to ischaemic heart disease. Adult Indians also have high triglyceride concentrations [27]. The source of the higher triglycerides has not been explained but is 
likely to be either from the placenta or the fetal liver. The excess maternal supply of NEFA may have increased triglyceride synthesis, but other fuels would be expected to be more important (e.g. lactate or alanine). Interestingly, high cord triglyceride but not NEFA concentrations are present at cordocentesis in growth-retarded babies [28], who are also hypoxaemic and hypoinsulinaemic. Thus, the high cord triglyceride concentration and small neonatal size could reflect the same processes in Indians as in growth-retarded babies.

Indians are prone to a central fat distribution [27]. Although this susceptibility may be present at birth, this study has shown that central fat deposition itself is not. Indeed, Indian babies appeared to have a global reduction in fat thickness. No differences in regional fat distribution were found in Polynesian babies. The smaller size of Indian babies was not explained by differences in maternal height, body mass index, glucose or NEFA. Similarly, the weight increase in pregnancy was similar for all ethnic groups and hence total calorie intake was unlikely to be important, particularly as maternal malnutrition needs to be extreme before birth weight is affected.

A previous study from the National Women's Hospital database (with poor identification of those with gestational diabetes) highlighted the smaller mean birth weight of Maori $(3.26 \mathrm{~kg}$ ) and European $(3.32 \mathrm{~kg})$ babies when compared with Pacific Island babies $(3.59 \mathrm{~kg})$ [22]. The current study excluded many of those likely to deliver smaller babies (smokers, hypertensive patients, those with concurrent systemic illness) and hence the current study possibly describes the baseline mean birth weight in these ethnic groups. The greater difference in mean birth weight in Maori and European babies between the two studies probably reflects the higher proportion who continue to smoke in pregnancy in these two ethnic groups. The absolute identification and exclusion of mothers with diabetes in pregnancy in the current study, would result in the exclusion of some larger babies from the normal subject groups. The mean body mass index and age of each ethnic group in the National Women's Hospital study [22], was similar to those in the current study, highlighting the representativeness of the pregnancies described here.

In conclusion, these results indicate two possible processes predisposing to NIDDM, in addition to genetic factors. One mechanism, in Indians, is consistent with the intra-uterine malnutrition hypothesis of Hales and Barker [11]. The other, in the offspring of Polynesians, is consistent with observations [12] relating to intra-uterine exposure to maternal hyperglycaemia in Pima Indians. Maternal obesity and subsequent abnormal glucose homeostasis in pregnancy may independently predispose Pacific Island and Maori populations to NIDDM. If this is the case, weight and glucose control before and during preg- nancy may be vital to control current epidemics of NIDDM in these populations.

Acknowledgements. DS was the AMP diabetes research fellow. Assays were funded from the Novo-Nordisk award and Bristol Myers Squibb and kindly performed by the Endocrinology Laboratory at Auckland Hospital and Biochemistry Laboratory at Middlemore Hospital. Thanks also go to the staff at Middlemore and National Women's Hospitals and St Helens antenatal clinic without whom this project would not have been possible. Particular thanks go to Ms. Caroline Conroy, diabetes midwife educator.

\section{References}

1. O'Sullivan JB; Mahan CM (1964) Criteria for the oral glucose tolerance test in pregnancy. Diabetes 13: 278-285

2. Zimmet $P$ (1982) Type 2 (non-insulin dependent) diabetes - an epidemiological overview. Diabetologia 22: 399-411

3. Lundgren H, Bengtsson C, Blohme G, Lapidus L, Waldenstrom J (1990) Fasting serum insulin concentration and early insulin response as risk determinants for developing diabetes. Diabetic Med 7: 407-413

4. Haffner SM, Stern MP, Mitchell BD, Hazuda HP, Patterson JK (1990) Incidence of type II diabetes in Mexican Americans predicted by fasting insulin and glucose levels, obesity and body fat distribution. Diabetes 39: 283-288

5. Lillioja S, Mott DM, Zawadzki JK et al. (1988) In vivo insulin action is a familial characteristic in non-diabetic Pima Indians. Diabetes 36: 1329-1335

6. Simmons D, Powell MJ (1993) Metabolic and clinical characteristics of South Asians and Europeans in Coventry. Diabetic Med 10: 751-758

7. Aronoff SL, Bennett PH, Gorden P, Rushforth N, Miller M (1977) Unexplained hyperinsulinaemia in normal and 'prediabetic' Pima Indians compared with normal Caucasians. Diabetes 26: 827-840

8. White K, Gracey M, Schumacher L, Spargo R, Kretchmer N (1990) Hyperinsulinaemia and impaired glucose tolerance in young Australian aborigines. Lancet I: 735

9. Hales CN, Barker DJP, Clark PMS, Cox LJ, Fall C, Osmond C, Winter PD (1991) Fetal and infant growth and impaired glucose tolerance at age 64 years. BMJ 303: 1019-1022

10. Barker DJP, Hales CN, Fall CHD, Osmond C, Phipps K, Clark PMS (1993) Type 2 (non-insulin-dependent) diabetes mellitus, hypertension and hyperlipidaemia (syndrome $X)$ : relation to reduced fetal growth. Diabetologia 36: 62-67

11. Hales CN, Barker DJP (1992) Type 2 (non-insulin-dependent) diabetes mellitus: the thrifty phenotype hypothesis. Diabetologia 35: 595-601

12. Pettitt DJ, Bennett PH, Saad MF, Charles MA, Nelson RG, Knowler WC (1991) Abnormal glucose tolerance during pregnancy in Pima Indian women: long term effects on offspring. Diabetes 40 [Suppl 2] 126-130

13. Scragg R, Baker J, Metcalf P, Dryson E (1991) Prevalence of diabetes mellitus and impaired glucose tolerance in a New Zealand multiracial workforce. N Z Med J 104: 395397

14. Court DJ, Mann SL, Stone PR, Goldsbury SM, Dixon McIvor D, Baker JR (1985) Comparison of glucose polymer and glucose for screening and tolerance tests in pregnancy. Obstet Gynecol 66: 491-499

15. Dubowitz LMS, Dubowitz V, Goldberg C (1970) Clinical assessment of gestational age in the newborn infant. J Pediatr 77: 1-10 
16. McCutcheon SN, Bauman DE (1986) Effect of chronic growth hormone treatment on responses to epinephrine and thyrotropin releasing hormone in lactating cows. J Dairy Sci 69: 44-51

17. DeFronzo RA (1988) The triumvirate: $\beta$ cell, muscle, liver. A collusion resonsible for NIDDM. Diabetes 37: 667-685

18. Balarajan R, Botting B (1989) Perinatal mortality in England and Wales: variation by mother's country of birth (1982-85). Health Trends 21: 79-84

19. Susa JB, Neave C, Sehgal P, Singer DB, Zeller WP, Schwartz R (1984) Chronic hyperinsulinaemia in the fetal rhesus monkey: effects of physiologic hyperinsulinaemia on fetal growth and composition. Diabetes 33: 656-660

20. McKeigue PM, Miller GJ, Marmot MG (1989) Coronary heart disease in South Asians overseas - a review. J Clin Epidemiol 42: 597-609

21. Tukuitonga CF, Stewart A, Beaglehole R (1990) Coronary heart disease among Pacific Island people in New Zealand. N Z Med J 103: 448-449

22. Simmons D, Baker J, James A, Roberts A (1992) Has the process causing non-insulin dependent diabetes started at birth? Evidence in neonates from a population with a high prevalence of diabetes. N Z Med J 105: 326-328
23. Nelson RG, Sievers ML, Knowler WC et al. (1990) Low incidence of fatal coronary heart disease in Pima Indians despite high prevalence of non-insulin dependent diabetes. Circulation 81: 987-995

24. Pettitt DJ, Knowler WC, Baird HR, Bennett PH (1980) Gestational diabetes: infant and maternal complications of pregnancy in relation to third trimester glucose tolerance in Pima Indians. Diabetes Care 3: 458-464

25. Aerts L, Holemans K, Van Assche FA (1990) Maternal diabetes during pregnancy: consequences for the offspring. Diabetes Metab Rev 6: 147-167

26. Gauguier D, Bihoreau M-T, Ktorza A, Berthault M-F, Picon L (1990) Inheritance of diabetes mellitus as a consequence of gestational hyperglycaemia in rats. Diabetes 39: 734-739

27. McKeigue PM, Shah B, Marmot MG (1991) Relation of central obesity and insulin resistance with high diabetes prevalence and cardiovascular risk in South Asians. Lancet 337: 382-386

28. Economides DL, Crook D, Nicolaides KH (1990) Hypertriglyceridaemia and hypoxemia in small for gestational age fetuses. Am J Obstet Gynecol 162: 382-386 